\title{
Kinetics of Silicon Oxidation from Liquid Iron Droplets*
}

\author{
By Nobuo SANO** and Yukio MATSUSHITA**
}

\begin{abstract}
Synopsis
A levitation technique was applied to the kinetic studies on the desiliconization of liquid iron-silicon alloys from 0.15 to $10.60 \% \mathrm{Si}$ at temperatures from $1550^{\circ}$ to $1800^{\circ} \mathrm{C}$, by using gas mixtures containing $\mathrm{CO}_{2}$ or $\mathrm{O}_{2}$ with $\mathrm{He}$ as a diluent. Gaseous $\mathrm{SiO}$ was found to be a reaction product at higher temperatures and at lower oxygen potentials, the reaction being controlled by gaseous diffusions of both $\mathrm{CO}_{2}$ and $\mathrm{SiO}$ to or from the surface of a droplet. The rates were interpreted in terms of well established mass transfer correlations for a gas flowing past around a sphere. The formation of solid or liquid oxide at lower temperatures was explained by the diffusion of oxygen ion through the oxide layer.
\end{abstract}

\section{Introduction}

The rate of oxidation of silicon in liquid iron is very important in the processes of refining and teeming of steel. The same is true with carbon and many investigators $^{11}$ have shown that the rate of decarburization is controlled by gaseous diffusion. The present investigation has been undertaken to study the mechanism of desiliconization, where two kinds of oxide, gaseous $\mathrm{SiO}$ and liquid or solid $\mathrm{SiO}_{2}$ have the possibility to be formed, depending upon the oxidizing conditions. The presence of these phases leads to a more complex situation than that found with carbon where only a gaseous oxide is formed.

\section{Experimental}

In order to avoid crucible contamination which would affect seriously the composition of the oxidation

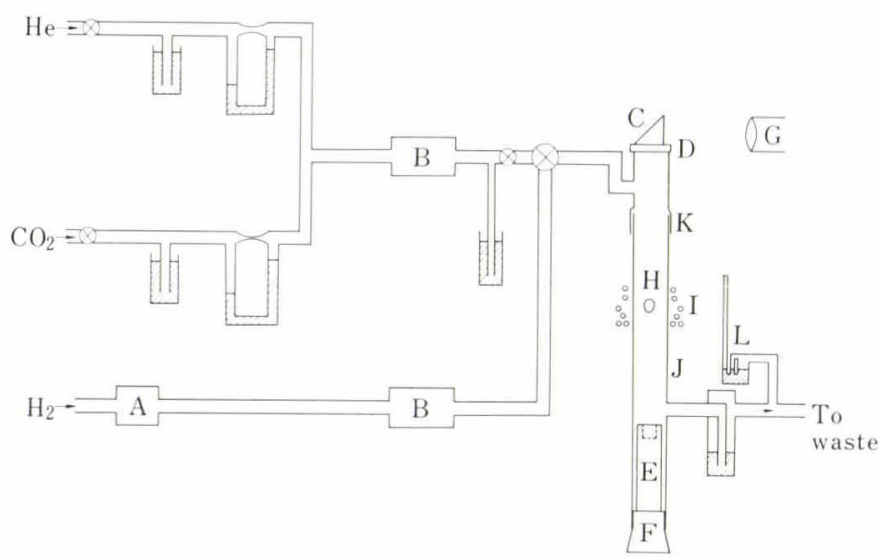
(A) Platinum catalyst
(G) Optical pyrometer
(B) $\mathrm{Mg}\left(\mathrm{ClO}_{4}\right)_{2}$
(H) Levitated droplet
(C) $\quad 45^{\circ}-90^{\circ}$ prism
(I) Levitation coil
(D) Optical flat
(E) Copper mold
(J) $15 \mathrm{~mm}$ vycor reaction tube
(K) Ground glass union
(F) Rubber stopper
(L) Manometer

Fig. 1. Schematic diagram of the apparatus product, a levitation melting technique was used with a $15 \mathrm{~kW}$ generator having a frequency of $300 \mathrm{kc} / \mathrm{sec}$.

The reaction tube made of Vycor tubing (O.D. $1.50 \mathrm{~cm}$, I.D. $1.28 \mathrm{~cm}$ ) shown in Fig. 1 consisted of two sections joined by a ground glass union. The upper section contained the gas inlet and an optical flat to view the upper surface of the droplet. The lower section contained the reaction zone, a copper mold and a gas outlet. The coil for levitation was mounted externally to the reaction tube and had seven turns made of $3 \mathrm{~mm}$ O.D. thin walled copper tubing, based on a design of Baker, Warner, and Jenkins. ${ }^{1)}$ For better water cooling of the coil, its wall was thinned by passing nitric acid solution and compressed water was used as well.

The flow rates of $\mathrm{He}, \mathrm{CO}_{2}$, and $\mathrm{H}_{2}$ were accurately controlled by means of needle valves to maintain the gas composition constant. Gases were purified by magnesium perchlorate, ascalite and magnesium chips heated at $600^{\circ} \mathrm{C}$ before leading to the reaction tube. Herium was used as a diluent and a coolant, because otherwise a temperature would rise beyond control.

Temperature were controlled to within $\pm 10^{\circ} \mathrm{C}$ by adjusting the power input except when the surface of the droplet was completely covered with oxidation product. It was measured continuously with a two color optical pyrometer which had been previously calibrated against the melting point of iron.

Specimens of iron-silicon alloys weighing 0.7 to $1.4 \pm 0.01 \mathrm{~g}$ were levitated under the atmosphere of hydrogen for deoxidation while $\mathrm{He}-\mathrm{CO}_{2}$ or $-\mathrm{O}_{2}$ was going to waste. After the surface of the droplet was cleaned for $1 \mathrm{~min}$, the reactive gas was introduced to the reaction tube by turning the changeover cock. After the lapse of various times up to $40 \mathrm{~min}$, the droplets were solidified as rapidly as possible at a levitated state by increasing the flow rate of helium and the power supply to give more levitation force, in fear that the oxidation product should be entrapped in a metallic phase during the direct quenching into a mold. The specimens thus obtained were chemically analysed for silicon, after the metal was separated from oxide. The contents of iron and silicon in the oxidation products were also determined when the amount was sufficient.

\section{Results and Discussion}

1. Formation of Solid or Liquid Oxide

Specimens weighing $1.4 \mathrm{~g}$ and containing initially

\footnotetext{
* Received September 7, 1970.

** Department of Metallurgy and Materials Science, University of Tokyo, Bunkyo-ku, Tokyo 113.
} 
$1.22,1.32$, or $1.64 \% \mathrm{Si}$ were held at $1550^{\circ} \mathrm{C}$ in $\mathrm{He}-\mathrm{CO}_{2}$ or $\mathrm{O}_{2}$, flowing at $500 \mathrm{ml} / \mathrm{min}$ for various times. The temperature rose by about $100^{\circ} \mathrm{C}$ due to the initial exothermic reaction and then it was controlled to a desired value. The droplets gradually were covered with oxide, starting from a film like interference fringe to a thick oxide layer (Photo. 1). As the amount of oxide increased, it tended to collect on the underside of the droplet and finally caused it to fall, the balance between its weight and the levitation force being lost. The chemical analysis showed that the oxide formed by $\mathrm{He}-\mathrm{CO}_{2}$ was iron silicate containing 50 to $55 \mathrm{wt} \%$ FeO (nearly saturated with silica), independently of time.

A series of desiliconization curves was obtained, as shown in Fig. 2. Each point represents at least three separate experiments. Roughly speaking, the plots seem to be parabolic with time. The rate increases with increasing oxygen potential of the reactive gas in order of $\mathrm{CO}_{2}-\mathrm{CO}, \mathrm{CO}_{2}$, and $\mathrm{O}_{2}$. Samples containing $50 \mathrm{mg} \mathrm{CaO}$ powder were also oxidized under the same conditions as before and the greater desiliconization rate by a factor of 3.4 was obtained (Fig. 3).

The parabolic behaviors of desiliconization support the view that the diffusion of a particular species in the formed oxide layer controls the rate of the reaction. Supposing that the oxide shell is thin enough to be treated as a plain plate, for the sake of simplicity, the
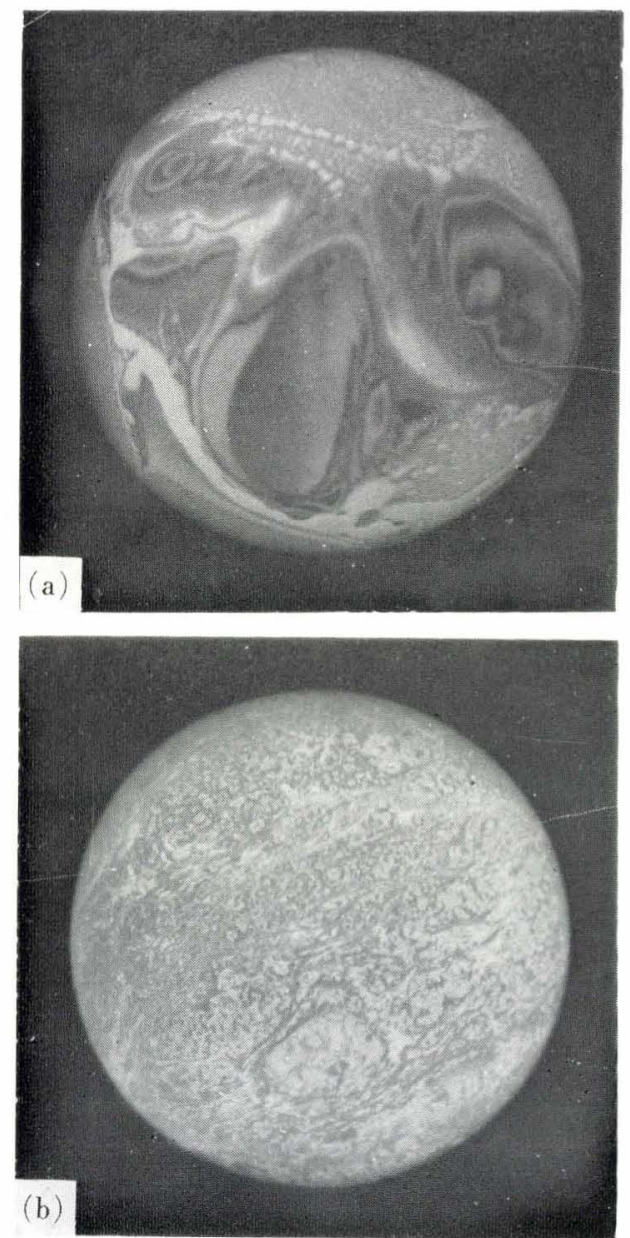

Photo. 1. Photographs of the upside of the droplet $(\times 70)$ $\left(P_{\mathrm{CO}_{2}}=0.05 \mathrm{~atm}, 550 \mathrm{ml} / \mathrm{min}, 15.50^{\circ} \mathrm{C}\right)$ following rate equation is obtained.

$$
\mathcal{N}_{\mathrm{Si}}=a \mathcal{N}_{\mathrm{C}}=\frac{a D_{\mathrm{C}} A\left(C_{1}-C_{2}\right)}{l}
$$

Mass balance between the metallic and oxide phases gives,

$$
\frac{A l\left(C_{1}+C_{2}\right)}{2}=\frac{\left(S_{O}-S\right) V}{a}
$$

where $\mathrm{Fe}^{3+}, \mathrm{Fe}^{2+}, \mathrm{Si}^{4+}$, or $\mathrm{O}^{2-}$, being considered as a diffusing species, give $0.75,0.5,1.0$, and 0.5 as the value of $a$, respectively. Combining Eqs. (1) and (2), it yields,

$$
\mathcal{N}_{\mathrm{Si}}=\frac{D_{\mathrm{C}}\left(C_{1}^{2}-C_{2}^{2}\right)}{2\left(S_{O}-S\right)} \cdot\left(\frac{A}{V a}\right)^{2}
$$

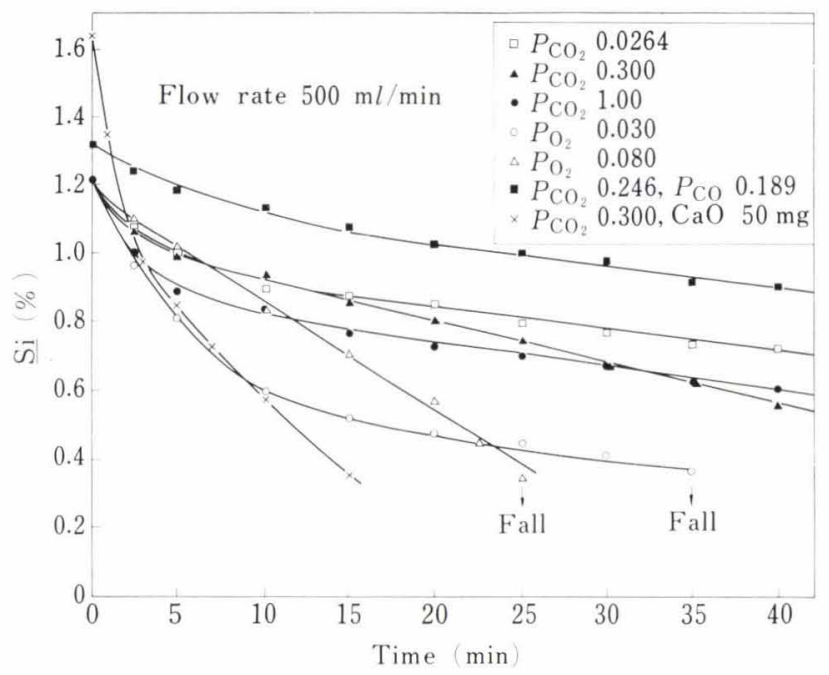

Fig. 2. Oxidation of iron-1.2, 1.3 , or $1.6 \%$ silicon droplets by various oxidizing gases at $1550^{\circ} \mathrm{C}$

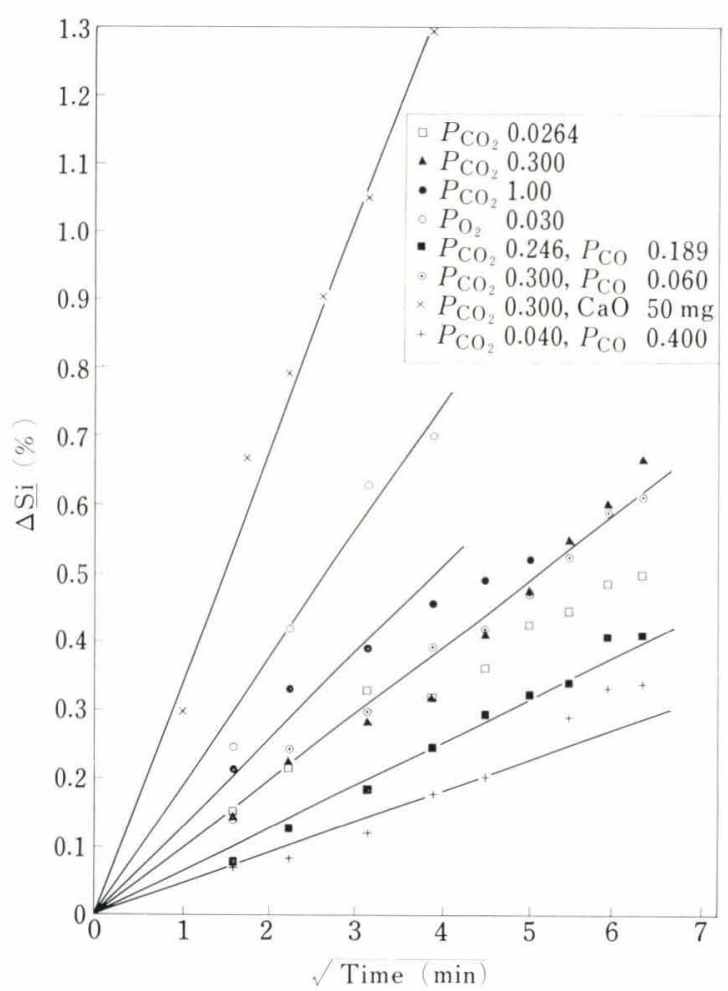

Fig. 3. Analysis of the data in Fig. 2 according to Eq. (4) 
Converting the unit of silicon content from moles $/ \mathrm{cm}^{3}$ to $\mathrm{wt}^{\%}$ and integrating Eq. (3), the change in silicon content is expressed by Eq. (4).

$$
\lrcorner \underline{\mathrm{Si}}(\%)=\frac{16800 a}{d_{\rho} M} \sqrt{D_{\mathrm{C}}\left(C_{1}^{2}-C_{2}^{2}\right) t} .
$$

The linear relationships hold between $\mu \mathrm{Si}(\%)$ and $\sqrt{t}$ in Fig. 3 except the plots towards the end of some heats, as expected by Eq. (4). The difference among the slopes of the straight lines shown in Fig. 3 should be due to that in the oxide composition, because the slope of the straight line is related to $a \sqrt{ } D_{\mathrm{C}}\left(C_{1}^{2}-C_{2}^{2}\right)$. The value of $C_{1}$ was estimated for $P_{\mathrm{CO}_{2}}=0.3$ for example, by using the following numerical values and assuming oxygen ion as a diffusing species. $\left(a=0.5, D=10^{-6}\right.$ $\mathrm{cm}^{2} / \mathrm{sec}, d=0.72 \mathrm{~cm}, \rho$ at $1550^{\circ} \mathrm{C}=7.1 \mathrm{~g} / \mathrm{cm}^{3}$ and slope in Fig. $3=0.095 \% / \sqrt{ } \mathrm{min}$ ) If $C_{1} \gg C_{2}, 7.5 \times 10^{-3}$ moles $/ \mathrm{cm}^{3}$ was obtained for $C_{1}$. When $D=10^{-5} \mathrm{~cm}^{2}$ sec is taken, $C_{1}$ would be $2.4 \times 10^{-3} \operatorname{moles} / \mathrm{cm}^{3}$.

Gaskell ${ }^{2)}$ estimated from the density measurements of $\mathrm{FeO}-\mathrm{SiO}_{2}$ system that the concentrations of free oxygen ion are $1.3 \times 10^{-3}, 4.8 \times 10^{-3}$, and $6.4 \times 10^{-2}$ moles $/ \mathrm{cm}^{3}$ for 39,71 , and $10 \mathrm{wt}^{\mathrm{o}} \mathrm{FeO}$, respectively. Considering the average composition of the oxide, the obtained value of $C_{1}=2$ to $7 \times 10^{-3}$ moles $/ \mathrm{cm}^{3}$ seems to be in good agreement with Gaskell's estimation. Any of $\mathrm{Fe}^{2+}, \mathrm{Fe}^{3+}$, and $\mathrm{Si}^{4+}$ was found to be impossible to be a diffusing species by the similar discussions.

As for the effect of lime, both the higher diffusivity and concentration of oxygen ion in a basic oxide presumably account for the higher reaction rate. The rapid desiliconization by oxygen is also explained by the formation of oxide richer in $\mathrm{FeO}$ (more than $60 \mathrm{wt} \%$ for the first $15 \mathrm{~min}$ ). Gases containing $\mathrm{CO}$ produced solid silica with little amount of $\mathrm{FeO}$. The reaction proceeded more slowly owing to the less diffusivity and concentration of $\mathrm{O}=$ in the oxide.

\section{Gaseous Oxide Formation}

When the temperature was raised to $1700^{\circ} \mathrm{C}$ for instance, keeping other conditions unchanged, the considerable fuming was observed closely to the droplet surface, being accompanied by greyish brown deposit on the wall of the reaction tube, while the surface was free of any condensed oxide phases. The deposit was found to be solid $\mathrm{SiO}$ with a small amount of $\mathrm{FeO}$ from the weight change at complete combustion in the air.

The silicon contents of the droplets changed linearly with time until the surface was covered with liquid iron silicate, as shown in Fig. 4. This behavior is similar to that of decarburization, where mass transport of oxidizing gas is rate determining. The rate of desiliconization was far greater than those at lower temperatures, that calls attention to the diffusion of gases, namely $\mathrm{CO}_{2}$ as a reactant and $\mathrm{SiO}$ as a product.

Effects of Partial Pressure of $\mathrm{CO}_{2}$ and Initial Silicon Concentration

The reaction rates for the first $1 \mathrm{~min}$ were determined by both the chemical analysis of silicon content and the change in the weight of specimen. They are plotted as functions of $P_{\mathrm{CO}_{2}}$ in $\mathrm{He}$ (Fig. 5 (a)) and the initial silicon concentration (Fig. $5(\mathrm{~b})$ ). The rate increases with increasing $P_{\mathrm{CO}_{2}}$ until the surface is covered completely with iron silicate and the desiliconization virtually ceases. The approximate critical $P_{\mathrm{CO}_{2}}$ was found to be $0.16 \mathrm{~atm}$ for $1.32 \% \mathrm{Si}$ specimens and $0.10 \mathrm{~atm}$ for $5.85 \% \mathrm{Si}$ at $1700^{\circ} \mathrm{C}, 500 \mathrm{ml} / \mathrm{min}$. With the more initial silicon concentration, the greater rate was obtained until reaching a limit. These findings differ from those of decarburization, where the rate is independent of the initial carbon concentration. This seems to be inconsistent with the linear behavior of the reaction theoretically, but the influence of the previous deposit on gaseous diffusion might be responsible, as the reaction proceeded.

The value of $P_{\mathrm{CO}_{2}} / \dot{n}$ was plotted against $P_{\mathrm{CO}_{2}}$ in Fig. 6 for all experiments. It shows that the linear relationship holds below the critical $P_{\mathrm{CO}_{2}}$ and the slopes of straight lines depend on the flow rate, the initial silicon concentration, and the weight of specimen.

In order to explain these observations, the following reaction mechanism was considered phenomenological-

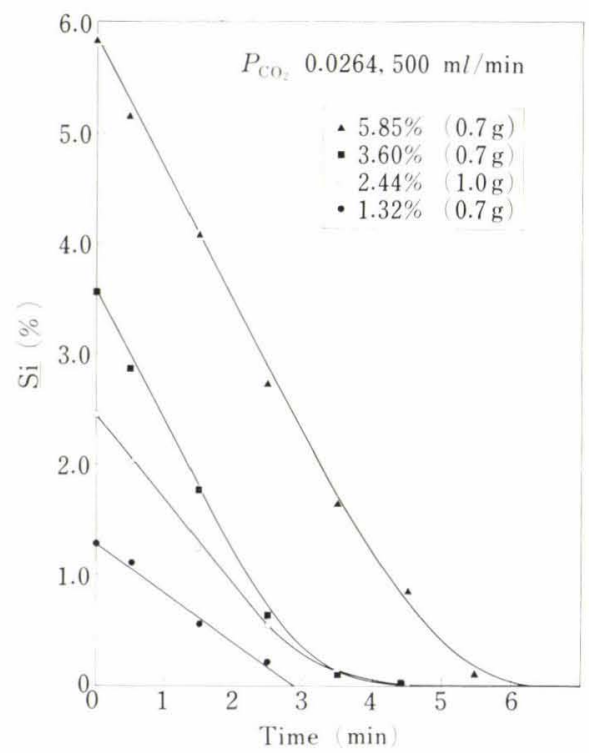

Fig. 4. Effect of the initial composition of iron-silicon droplets on the oxidation rate of silicon at $1700 \mathrm{C}$

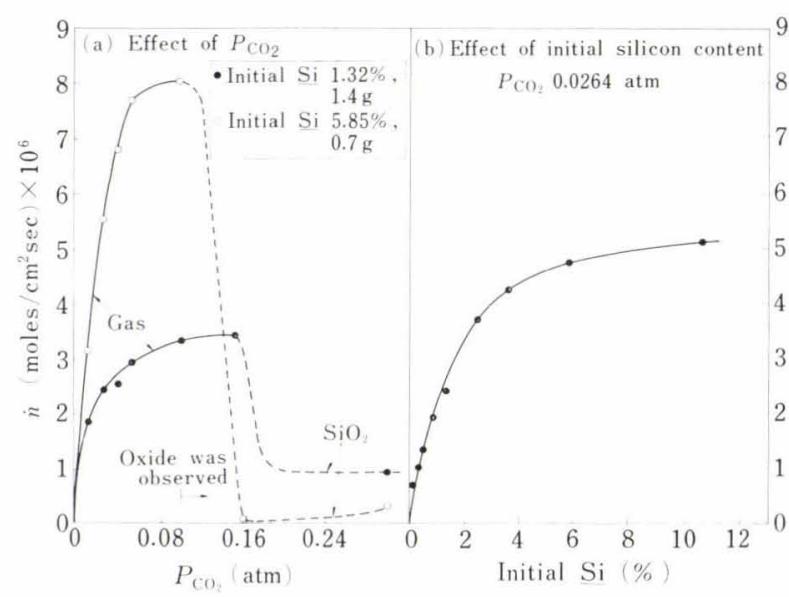

Fig. 5. Effect of $P_{\mathrm{CO}}$, and initial silicon content on desiliconization rates $(1700 \mathrm{C}, 500 \mathrm{~m} / / \mathrm{min})$ 


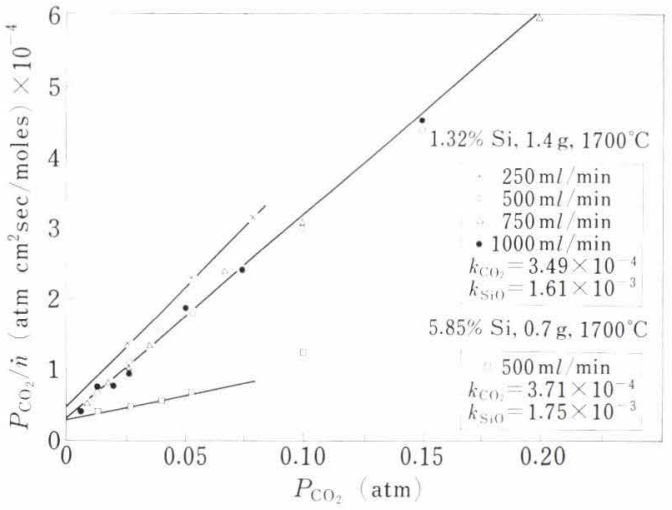

Fig. 6. Analysis of desiliconization rates according to Eq. (6)

ly.

$$
\begin{aligned}
\underline{\mathrm{Si}}+2 \mathrm{CO}_{2} & =\mathrm{SiO}_{2}+2 \mathrm{CO} \\
\mathrm{SiO}_{2}+\underline{\mathrm{Si}} & =2 \mathrm{SiO}
\end{aligned}
$$

Firstly, the reaction between $\mathrm{CO}_{2}$ and $\underline{\mathrm{Si}}$ in metal to form $\mathrm{SiO}_{2}$ as an intermediate compound would occur on the surface of droplet and then $\mathrm{SiO}_{2}$ would be reduced by $\underline{\mathrm{Si}}$ to form $\mathrm{SiO}$ gas. The detailed mechanism is not considered here. Assuming the rapid diffusion of $\underline{\mathrm{Si}}$, the establishment of chemical equilibria and the steady state of each reaction, the reciprocal of $n$ is expressed approximately by Eq. (5), where the resistance terms of mass transport of gases in two steps are added.

$$
\frac{1}{\dot{n}}=\frac{1}{k_{\mathrm{CO}_{2}} P_{\mathrm{CO}_{2}}}+\frac{1}{k_{\mathrm{Si}} K_{2} \sqrt{ } a_{\mathrm{Si}}}
$$

where $K_{2}$ denotes the equilibrium constant of reaction (II), $P_{\mathrm{sio}} / \sqrt{a_{\mathrm{Si}}}$. Multiplying both sides of Eq. (5) by $P_{\mathrm{CO}_{2}}$, Eq. (6) is obtained.

$$
\frac{P_{\mathrm{CO}_{2}}}{\dot{n}}=\frac{1}{k_{\mathrm{CO}_{2}}}+\frac{1}{k_{\mathrm{SiO}} K_{2} \sqrt{ } a_{\mathrm{Si}}} \cdot P_{\mathrm{CO}_{2}}
$$

It is expected that $P_{\mathrm{CO}_{2}} / \dot{n}$ changes with $P_{\mathrm{CO}_{2}}$ in a linear manner, the intercept with the axis and the slope giving the values of $1 / k_{\mathrm{CO}_{2}}$ and $1 / k_{\mathrm{SiO}} K_{2} \sqrt{a_{\mathrm{si}}}$, respectively. Similarly, Eq. (7) is obtained from Eq. (5), yielding the linear relationship between $\sqrt{a_{\mathrm{si}}} \mid \dot{n}$ and $\sqrt{a_{\mathrm{Si}}}$.

$$
\underset{\dot{n}}{a_{\mathrm{Si}}}=\frac{1}{k_{\mathrm{SiO}} K_{2}}+\frac{1}{k_{\mathrm{CO}_{2}} P_{\mathrm{CO}_{2}}} \cdot \sqrt{a_{\mathrm{Si}}}
$$

This also gives $1 / k_{\mathrm{SiO}} K_{2}$ and $1 / K_{\mathrm{CO}_{2}} P_{\mathrm{CO}_{2}}$ by the intercept and slope. The numerical values of $k_{\mathrm{CO}_{2}}$ and $k_{\mathrm{SiO}}$ obtained from the above two relations (Eqs. (6) and (7)) should agree, as far as the assumptions for the reaction mechanism are reasonable.

For $k_{\mathrm{CO}_{2}}$ and $k_{\mathrm{siO}}, 3.49 \times 10^{-4}$ and $1.61 \times 10^{-3}$ moles $\mathrm{cm}^{2} \mathrm{sec}$ atm were respectively obtained from Fig. 6, for $1.4 \mathrm{~g}$ specimens with $1.32 \%$ initial silicon at flow rates from 500 to $1000 \mathrm{ml} / \mathrm{min}$, because the flow rate dependence was not significantly observed in this range. The flow rate of $250 \mathrm{ml} / \mathrm{min}$ gave less values for both $k_{\mathrm{CO}_{2}}$ and $k_{\mathrm{SiO}}$, namely $2.86 \times 10^{-4}$ and $1.43 \times$ $10^{-3}$ moles $/ \mathrm{cm}^{2} \mathrm{sec}$ atm. The figure also gives $3.71 \times$

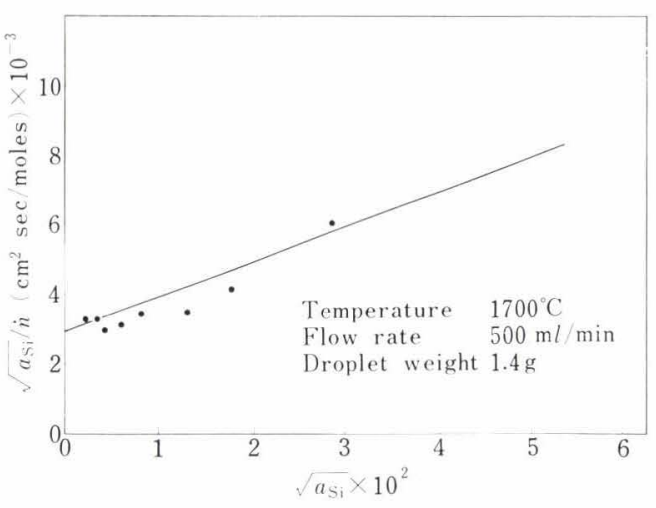

Fig. 7. Analysis of desiliconization rates according to Eq (7)

$10^{-4}$ and $1.36 \times 10^{-3} \mathrm{moles} / \mathrm{cm}^{2} \mathrm{sec}$ atm to $k_{\mathrm{CO}_{2}}$ and $k_{\text {sio }}$ for $0.7 \mathrm{~g}$ specimens with $5.85 \%$ silicon at $500 \mathrm{ml}$ min. Here, $K_{2}$ of 0.250 was used according to JANAF thermochemical tables. ${ }^{3)}$ Densities of iron-silicon alloys were referred to Dzhemilev, Popel', and Tsarewskiy, ${ }^{4)}$ and the values reported by Chipman and Baschwitz ${ }^{12)}$ were used as the activities of silicon, assuming a regular behavior.

Figure 7 shows the effect of initial silicon activity according to Eq. (7), where a straight line is drawn on the basis of $k_{\mathrm{CO}_{2}}$ and $k_{\mathrm{sio}}$ obtained from Fig. 6. The validity of Eq. (5) is confirmed by the fact that the plots are not very far from the line.

The measured values of $k_{\mathrm{CO}_{2}}$ are now discussed in the light of the estimation by the empirical mass transfer correlation for a gas flowing past around a sphere, which was applied to the decarburization rates by Distin, Hallet, and Richardson. ${ }^{51}$

$$
S h=2+0.5\left(G r^{\prime} \cdot S c\right)^{0.25}+n\left(\operatorname{Re} \cdot S c^{0.5}\right)^{0.62}
$$

where,

$$
G r^{\prime}=G r_{M}+\left(\frac{S c}{P r}\right)^{0.5} \cdot G r_{H}
$$

The first term of Eq. (8) expresses the effect of radial diffusion, the second of natural convection, and the third of forced convection. The average of room, $T b$ and droplet surface temperatures, $T_{0}$ was used for a film temperature $T_{f}$. The values of diffusivity $D$. viscosity $\mu$, and thermal conductivity $k^{\prime}$ for the mixed gas were estimated according to Bird, Stewart, and Lightfoot. ${ }^{6)}$ The numerical values of the physical properties used are listed below for desiliconization by $P_{\mathrm{CO}_{2}}$ of $0.0264 \mathrm{~atm} . T_{f}=1133^{\circ} \mathrm{K}, D=5.53 \mathrm{~cm}^{2} / \mathrm{sec}$, $\mu=4.27 \times 10^{-4}$ poise, $k^{\prime}=7.35 \times 10^{-4} \mathrm{cal} / \mathrm{cm} \mathrm{sec}{ }^{\circ} \mathrm{K}$, $C_{p}=1.03 \mathrm{cal} / \mathrm{g}^{\circ} \mathrm{K}, \quad \rho=5.44 \times 10^{-5} \mathrm{~g} / \mathrm{cm}^{3}, \quad \rho_{M}=6.83 \mathrm{~g} /$ $\mathrm{cm}^{3}(1.32 \% \mathrm{Si}), \quad 6.51 \mathrm{~g} / \mathrm{cm}^{3}(5.85 \% \mathrm{Si}), \quad d=0.731 \mathrm{~cm}$ $(1.32 \% \mathrm{Si}, \quad 1.4 \mathrm{~g}), \quad 0.590 \mathrm{~cm} \quad(5.85 \%, \quad 0.7 \mathrm{~g}), \quad d_{T}=$ $1.28 \mathrm{~cm}$.

For $n$ in Eq. (8), 0.60 and 0.50 were respectively used for $0.7 \mathrm{~g}$ and $1.4 \mathrm{~g}$ specimens.

According to Eq. (8), the values of $S h$ and $k_{\mathrm{CO}_{2}}$ are estimated for given conditions. The estimated values of $k_{\mathrm{CO}_{2}}$ are shown in Fig. 8 for 1.4 and $0.7 \mathrm{~g}$ specimens separately as a function of (flow rate) $)^{0.62}$. Since the droplet is not so small as compared with the diameter of the reaction tube, the wall effects should not be 


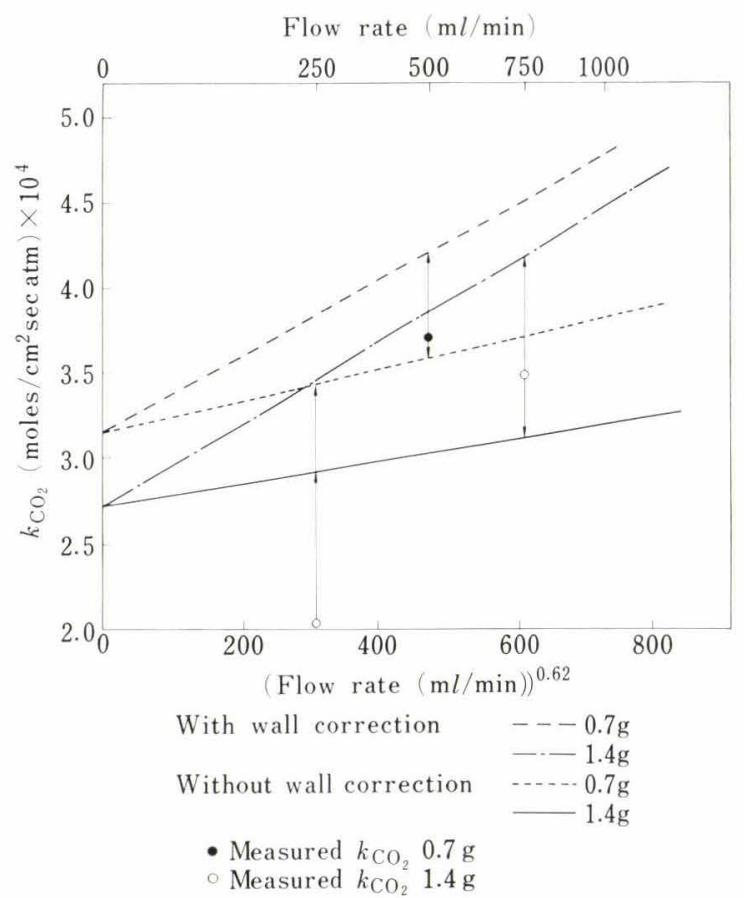

Fig. 8. Estimated and measured mass transfer coefficients

ignored. Citing the correction factors for friction force from a book of Happel and Brenner, ${ }^{7)}$ related to the ratio of diameters of a rigid sphere and a cylinder, linear velocity $U, R e$ and then $k_{\mathrm{CO}_{2}}$ were corrected, as shown in Fig. 8 . The measured $k_{\mathrm{CO}_{2}}$ lies between the estimate with wall correction and that without it. Taking into account that the correction should be made for a circulating liquid sphere, the measured and estimated values are considered to be in good agreement for both 0.7 and $1.4 \mathrm{~g}$ specimens. At $250 \mathrm{ml} / \mathrm{min}$, the measured rate is smaller than the estimate. As the flow rate is decreased, it is stoichiometrically impossible for the measured reaction rate to reach the estimate, because the supply of $\mathrm{CO}_{2}$ is not sufficient, the efficiency of $\mathrm{CO}_{2}$ reaching $100 \%$.

\section{Condensation of $\mathrm{SiO}$}

It has been found by some investigators ${ }^{8)}$ that solid $\mathrm{SiO}$ is stable in a thermodynamic sense. Considering that the deposit was mainly solid $\mathrm{SiO}$ in this study, the condensation of $\mathrm{SiO}$ gas in the hydrodynamic boundary layer seems to be responsible for that the measured $k_{\mathrm{SiO}}$ is greater than $k_{\mathrm{CO}_{2}}$. The following is the estimation of the degree of supersaturation which was necessary for the condensation of $\mathrm{SiO}$, based on the concept of Turkdogan. ${ }^{9 !}$

Figure 9 is a schematic profile of temperature and $P_{\mathrm{SiO}}$ in the laminar boundary layer. The values of $P e$ and $P_{\mathrm{SiO}}$ at equilibrium, are determined thermodynamically when a temperature profile is known. If the supersaturation is required for the nucleation, the virtual vapor pressure $P n$ should be $s$ times greater than $P e$. The tangent to the curve $P n$ from the point $P_{0}$, which represents $P_{\mathrm{sio}}$ at the surface of droplet, should yield the flux of transport of $\mathrm{SiO}$ by convection-condensation process. Assuming that $\delta_{T}$, the boundary layer thickness for temperature is approximated by $\delta_{\mathrm{CO}_{2}}$, that for diffusion of $\mathrm{CO}_{2}$, which was obtained experi-

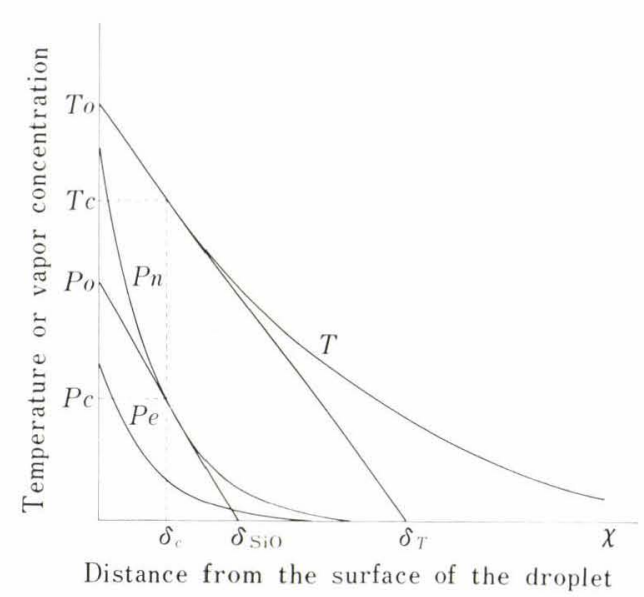

Fig. 9. Vapor concentration and temperature profiles in the boundary layer

mentally, the temperature profile is expressed by Eq. (9).

$$
T=T_{0}-\frac{T_{0}-T b}{\delta_{\mathrm{CO}_{2}}} \chi
$$

The boundary layer thicknesses $\delta_{\mathrm{CO}_{2}}$ and $\delta_{\mathrm{sio}}$ are expressed by the definition.

$$
\delta_{\mathrm{CO}_{2}}=\frac{D_{\mathrm{CO}_{2}}}{R T_{j} k_{\mathrm{CO}_{2}}}, \quad \delta_{\mathrm{sio}}=\frac{D_{\mathrm{siO}}}{R T_{l} k_{\mathrm{sio}}} .
$$

where

$$
T_{l}=\frac{\left(T_{0}+T_{c}\right)}{2}
$$

From Eq. (10), Eq. (11) is derived by using that the gas diffusivity is proportional to $T^{1.5}$.

$$
\begin{aligned}
\frac{\delta_{\mathrm{SiO}}}{\delta_{\mathrm{CO}_{2}}} & =\frac{\left(D_{\mathrm{SiO}}\right) T_{i}}{\left(D_{\mathrm{CO}_{2}}\right) T_{f}} \cdot \frac{k_{\mathrm{CO}_{2}}}{k_{\mathrm{SiO}}} \cdot \frac{T_{f}}{T_{l}} \\
& =\left(\frac{D_{\mathrm{SiO}}}{D_{\mathrm{CO}_{2}}}\right)_{T_{f}} \cdot \frac{k_{\mathrm{CO}_{2}}}{k_{\mathrm{SiO}}} \cdot\left(\frac{2 T_{f}}{T_{c}+T_{0}}\right)^{0.5} \ldots
\end{aligned}
$$

The tangent from $P_{0}$ to the curve $P n$ is

$$
\frac{P_{0}}{\delta_{\mathrm{SiO}}}=\frac{d P n}{d \chi}=s \frac{d P e}{d \chi} \mid \frac{d T}{d \chi}=s \frac{d P e}{d \chi} \cdot \frac{\hat{o}_{\mathrm{CO}_{2}}}{T_{0}-T b}
$$

by using $P n=s \cdot P e$ and Eq. (9).

Distance beyond which condensation occurs, $\chi_{c}$ is defined by Eq. (13)

$$
\chi_{c}=\delta_{\mathrm{sio}}\left(1-\frac{P n}{P_{0}}\right) \ldots
$$

$P e$ is expressed by Eq. (14), according to Kubachewski, Evans, and Alcock. ${ }^{8)}$

$$
\log P_{e}=-c_{T}^{17750}-2.77 \log T+16.77
$$

Solving Eqs. (9), (11), (12), (13), and (14), the values of Tc, $P n, \delta_{c}$, and $s$ for the oxidation by $P_{\mathrm{CO}_{2}}$ of $0.0264 \mathrm{~atm}$ were estimated by using the measured $k_{\mathrm{CO}_{2}}$ and $k_{\mathrm{SiO}}$, $D_{\mathrm{SiO}} / D_{\mathrm{CO}_{2}}=1.07, T b=293^{\circ} \mathrm{K}$, and $T_{0}=1973^{\circ} \mathrm{K}$. $P_{o}$ was calculated by the measured rate $\dot{n}$ and Eq. (15).

$$
\dot{n}=k_{\mathrm{sio}} P_{0} \ldots
$$


Table 1. Summary of calculations for condensations of $\mathrm{SiO}\left(P_{\mathrm{CO}_{2}}=0.0264,500 \mathrm{ml} / \mathrm{min}, 1700^{\circ} \mathrm{C}\right)$

\begin{tabular}{|c|c|c|c|c|c|c|c|c|c|c|c|}
\hline \multirow{2}{*}{$\begin{array}{l}\text { Weight } \\
\text { (g) }\end{array}$} & \multirow{2}{*}{$\frac{\mathrm{Si}}{(\%)}$} & \multicolumn{2}{|c|}{$\begin{array}{c}k\left(\operatorname{moles} / \mathrm{cm}^{2} \mathrm{sec}\right) \\
\times 10^{4}\end{array}$} & \multirow{2}{*}{$\begin{array}{l}T_{c} \\
\left({ }^{\circ} \mathrm{K}\right)\end{array}$} & \multicolumn{2}{|c|}{$\delta(\mathrm{cm}) \times 10^{2}$} & \multirow{2}{*}{$\begin{array}{c}\chi_{c}(\mathrm{~cm}) \\
\times 10^{2}\end{array}$} & \multirow{2}{*}{$\begin{array}{l}P_{0}(\mathrm{~atm}) \\
\times 10^{4}\end{array}$} & \multirow{2}{*}{$\begin{array}{l}P e(\mathrm{~atm}) \\
\times 10^{4}\end{array}$} & \multirow{2}{*}{$\begin{array}{l}P n(\mathrm{~atm}) \\
\quad \times 10^{4}\end{array}$} & \multirow{2}{*}{$s$} \\
\hline & & $\mathrm{CO}_{2}$ & $\mathrm{SiO}$ & & $\mathrm{CO}_{2}$ & $\mathrm{SiO}$ & & & & & \\
\hline 0.7 & 5.85 & 3.71 & 17.5 & 1575 & 16.0 & 4.55 & 3.77 & 31.9 & 4.42 & 5.35 & 1.21 \\
\hline 1.4 & 1.32 & 3.49 & 16.1 & 1564 & 17.0 & 4.94 & 4.14 & 15.4 & 3.76 & 2.50 & 0.664 \\
\hline
\end{tabular}

The calculations are summarized in Table 1 for $0.7 \mathrm{~g}$ and $1.4 \mathrm{~g}$ specimens. The table shows that $\mathrm{SiO}$ condenses at the distance beyond $0.038 \mathrm{~cm}$ from the surface, for $0.7 \mathrm{~g}$ droplet, where the temperature is $1300^{\circ} \mathrm{C}$ and the partial pressure of $\mathrm{SiO}$ in $5.4 \times 10^{-4} \mathrm{~atm}$. The value of $s$ less than 1.00 in Table 1 is due probably to the rough approximations (See Appendix). It follows from this table that the homogeneous nucleation of solid $\mathrm{SiO}$ does not require great supersaturation. Thus, it is likely that the diffusion of $\mathrm{SiO}$ gas is enhanced by the nucleation-condensation process.

\section{Effect of Weight of Specimens}

Whichever of transports of $\mathrm{CO}_{2}$ and $\mathrm{SiO}$ may be more important in the reaction (see Eq. (5)), the ratio of total desiliconization rates between two specimens with different weights should be equal to that of mass transfer coefficients of gas, only if those of $\mathrm{CO}_{2}$ and $\mathrm{SiO}$ have the same dependence on the weight of specimen. Table 2 shows the agreement of experimental results with theoretical estimations for specimens with various initial silicon concentrations.

\section{Effect of Temperature}

The reaction rates are plotted against the reciprocal of absolute temperature for $1.32 \%$ and $5.85 \%$ ironsilicon alloys (Fig. 10). At $1800^{\circ} \mathrm{C}$ or higher, the vaporization of iron retarded seriously the silicon reaction by consuming $\mathrm{CO}_{2}$ to form FeO. At lower temperatures than $1650^{\circ} \mathrm{C}$, solid silica was formed and the rates were too small to be plotted in the figure. The apparant activation energy for $1.32 \% \mathrm{Si}$ at higher temperatures than $1700^{\circ} \mathrm{C}$ is $8.2 \mathrm{kcal} / \mathrm{mole}$, whereas it is $93.9 \mathrm{kcal} / \mathrm{mole}$ between $1650^{\circ}$ and $1700^{\circ} \mathrm{C}$. Suppose that $8.2 \mathrm{kcal} /$ mole corresponds to the temperature dependence of $k_{\mathrm{CO}_{2}}$ and $93.9 \mathrm{kcal} / \mathrm{mole}$ does to that of $K_{2} k_{\mathrm{siO}}$, the apparant activation energy of $k_{\mathrm{siO}}$ is calculated to be $20.6 \mathrm{kcal} / \mathrm{mole}$, taking account of $+73.6 \mathrm{kcal} / \mathrm{mole}$, a half of the enthalpy change of reaction (II). Although the transport of gas is not an activation process, the activation energy was calculated to be $6.2 \mathrm{kcal} / \mathrm{mole}$ apparantly in the temperature range concerned. However, this treatment of activation energies is not accurate enough to discuss the difference between the experimental estimations, and the theory for gas diffusion, owing to the lack of available data.

Consequently, it is presumed that the transport of $\mathrm{CO}_{2}$ in reaction $(\mathrm{I})$ controls the process more predominantly than that of $\mathrm{SiO}$ in reaction (II) a. higher temperatures and vice versa at lower temperaúu es.

\section{Estimation of Critical Conditions to Form Conclensed} Phases

Silicon content at oxide formation towards the end
Table 2. Rates of desiliconization $\left(\dot{n}\left(\mathrm{~mole} / \mathrm{cm}^{2} \mathrm{sec}\right) \times 10^{6}\right)$ related to specimen weights $\left(P_{\mathrm{CO}_{2}}=0.0264,500\right.$ $\mathrm{ml} / \mathrm{min}, 1700^{\circ} \mathrm{C}$ )

\begin{tabular}{c|c|c|c|c|c|} 
& & \multicolumn{5}{|c}{ Initial silicon concentration (\%) } \\
& & 1.32 & 2.45 & 3.60 & 5.85 \\
\hline \multirow{2}{*}{$\begin{array}{c}\text { Weight } \\
\text { (g) }\end{array}$} & 0.7 & 2.68 & & 4.72 & 5.54 \\
& 1.0 & & 3.98 & & \\
\multirow{3}{*}{ Ratio } & 1.4 & 2.44 & 3.78 & 4.28 & 4.76 \\
\cline { 2 - 6 } & Experimental & 1.10 & 1.05 & 1.10 & 1.16 \\
& Theoretical & 1.10 & 1.04 & 1.10 & 1.10
\end{tabular}

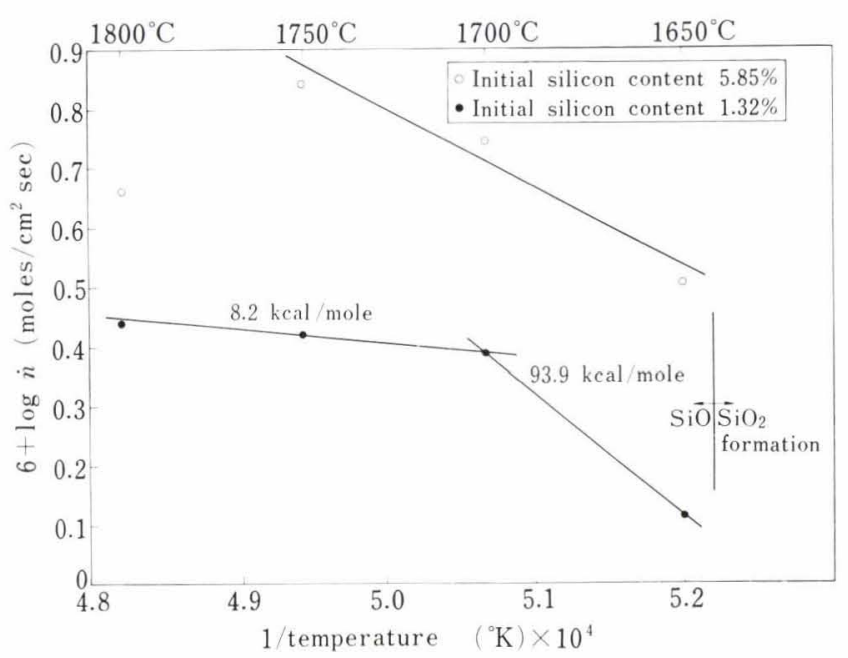

Fig. 10. Relationship between desiliconization rates and temperature $(1.4 \mathrm{~g}, 500 \mathrm{ml} / \mathrm{min})$

of the process is determined by the relative rate of the diffusion of silicon from the bulk of a droplet to the surface, compared with that of gas diffusion. The diffusion in a droplet is expressed by Eq. (16).

$$
-\frac{d \underline{\mathrm{Si}}(\%)}{d t}=\frac{A D_{\mathrm{Si}} \underline{\mathrm{Si}}(\%)}{V \check{\delta}_{M}}
$$

where the concentration at the surface was reasonably assumed to be zero at oxide formation. Choosing the results of $5.85 \% \mathrm{Si}$ specimens in Fig. 4 for example, the value of $D_{\mathrm{Si}} / \delta_{M}$ was obtained to be $3.3 \times 10^{-3} \mathrm{~cm} /$ sec, where $-d \underline{\mathrm{Si}} / d t=0.40 \mathrm{wt} \% / \mathrm{min}, \quad \underline{\mathrm{Si}}=0.18 \%$, $A / V=10.2 \mathrm{l} / \mathrm{cm}$ at oxide formation. $\delta_{M}$ is $1.5 \times$ $10^{-2} \mathrm{~cm}$, using $D_{\mathrm{Si}}=4.9 \times 10^{-5} \mathrm{~cm}^{2} / \mathrm{sec}$ at $1700^{\circ} \mathrm{C}$ by Calderon, Sano, and Matsushita. ${ }^{10)}$

Turkdogan, Grieveson, and Darken ${ }^{11)}$ evaluated the critical $P_{\mathrm{CO}_{2}}$ for a vaporization-oxidation process of metals, by equalizing the free vaporization rate of a 
metal in vacuo to the diffusion rate of $\mathrm{CO}_{2}$ under given hydrodynamic conditions. If this is the case in maintaining the surface of a droplet bare to form $\mathrm{SiO}$ gas, the critical $P_{\mathrm{CO}_{2}}$ is estimated to be $0.16 \mathrm{~atm}$. The agreement with the experiments (Fig. 5) is satisfactory.

\section{Conclusions}

The removal of silicon from liquid iron-silicon alloys using $\mathrm{CO}_{2}$ is predominantly controlled by gaseous diffusion when the conditions for the formation of $\mathrm{SiO}$ gas are satisfied. On the other hand, at lower temperatures and for higher $P_{\mathrm{CO}_{2}}$, the reaction product was found to be solid silica or liquid iron silicate, where the reaction proceeds far more slowly and the diffusion of oxygen ion in the oxide layer is rate controlling.

These observations are of great practical significance in relation to the mechanism of desiliconization in a basic oxygen furnace, where silicon initiates to be removed even before the complete slag formation. Very high temperature near the fire point seems to be favorable for gaseous oxide formation by $\mathrm{CO}_{2}$ as a combustion product of $\mathrm{CO}$.

\section{Acknowledgements}

Thanks are due to Dr. R. G. Ward, formerly, Professor, McMaster University, Hamilton, Ontario, Canada, and presently, Director of Research, Broken Hill Proprietary, Melbourne, Australia for helpful suggestions when one of the authors started this study at McMaster. The authors are also indebted to Miss Mizuko Iwata for her technical assistance.

A part of this work was presented at the International Conference of the Science and Technology on Iron and Steel held in September, 1970 in Tokyo.

\section{Nomenclature}

$A \quad$ : surface area $\left(\mathrm{cm}^{2}\right)$

a : molar equivalent of silicon to diffusing species $(-)$

$a_{\mathrm{Si}}:$ activity of silicon in iron-silicon alloy $(-)$

$C_{1} \quad$ : concentration of diffusing species at oxide-gas interface $\left(\right.$ moles $\left./ \mathrm{cm}^{3}\right)$

$C_{2}$ : concentration of diffusing species at oxide-metal interface $\left(\right.$ moles $\left./ \mathrm{cm}^{3}\right)$

$C_{p} \quad$ : heat capacity of gas $\left(\mathrm{cal} / \mathrm{g}^{\circ} \mathrm{K}\right)$

$D$ : diffusion constant $\left(\mathrm{cm}^{2} / \mathrm{sec}\right)$

d : diameter of droplet $(\mathrm{cm})$

$d_{T}$ : inner diameter of reaction tube $(\mathrm{cm})$

$g \quad$ : acceleration of gravity $\left(\mathrm{cm} / \mathrm{sec}^{2}\right)$

$h$ : heat transfer coefficient $\left(\mathrm{cal} / \mathrm{sec}^{\mathrm{cm}}{ }^{\circ} \mathrm{K}\right.$ )

$k$ : mass transfer coefficient (moles $/ \mathrm{cm}^{2} \mathrm{sec}$ atm)

$k^{\prime} \quad$ : thermal conductivity of gas $\left(\mathrm{cal} / \mathrm{sec} \mathrm{cm}{ }^{\circ} \mathrm{K}\right.$ )

$P \quad$ : partial pressure (atm)

$P e \quad$ : vapor pressure (atm)

$P n$ : vapor pressure required for nucleation (atm)

$S$ : concentration of silicon (moles $/ \mathrm{cm}^{3}$ )

$S_{0}$ : initial concentration of silicon $\left(\operatorname{moles} / \mathrm{cm}^{3}\right)$

$s \quad$ : degree of supersaturation $(-)$

$T$ : absolute temperature $\left({ }^{\circ} \mathrm{K}\right)$

$T_{c}$ : temperature at condensation of $\mathrm{SiO}\left({ }^{\circ} \mathrm{K}\right)$

$U \quad$ : linear velocity of gas in tube $(\mathrm{cm} / \mathrm{sec})$

$V \quad$ : volume of droplet $\left(\mathrm{cm}^{3}\right)$
\% : distance from the surface of droplet $(\mathrm{cm})$

$\chi_{c}$ : distance from the surface of droplet beyond which condensation occurs $(\mathrm{cm})$

$\delta \quad$ : boundary layer thickness $(\mathrm{cm})$

$\mu \quad$ : gas viscosity ( $\mathrm{g} / \mathrm{cm} \mathrm{sec})$

$\rho \quad$ : density $\left(\mathrm{g} / \mathrm{cm}^{3}\right)$

$G r_{H}$ : Grashof number for heat transfer $\left(g d^{3} o_{f}^{2}\left(T_{o}-T_{b}\right)\right.$ $\left.\mu_{f}^{2} \cdot T_{f}\right)$

$G r_{M}$ : Grashof number for mass transfer $\left(g d^{3} o_{f}\left(o_{o}\right.\right.$ $\left.\left.-o_{b}\right) \mu_{f}^{2}\right)$

$N u$ : Nusselt number $\left(h d / k^{\prime}\right)$

$\operatorname{Pr} \quad$ : Prandl number $\left(\left(\mu C_{p} / k^{\prime}\right)_{f}\right)$

Re : sphere Reynolds number $\left(\rho_{j} U d / \mu_{f}\right)$

$S_{c} \quad$ : Schmidt number $\left((\mu / \rho D)_{f}\right)$

Sh : Sherwood number $(k d / D)$

Subscripts

b : property in bulk gas

c : property of diffusing species

$f \quad$ : property at film temperature $T_{\text {, }}$

$M$ : property in metal phase

$o \quad$ : property at surface of droplet

\section{REFERENCES}

1) L. A. Baker, N. A. Warner, and A. E. Jenkins: Trans. TMS-AIME, 230 (1964), 1223.

2) D. R. Gaskell: Private communication.

3) JANAF Thermochemical Tables PB 168370: Dow Chemical Company, distributed by Clearinghouse, Springfield, Va.

4) N. K. Dzhemilev, S. I. Popel', and B. V. Tsarewskiy: FIZ Metal Metalloved, 18 (1964), 83.

5) P. A. Distin, G. D. Hallet, and F. D. Richardson: JISI. 206 (1968), 821.

6) R. B. Bird, W. E. Stewart, and E. N. Lightfoot: Transport Phenomena, (1960), John Wiley and Sons, New York.

7) J. Happel and H. Brenner: Low Reynolds Number Hydrodynamics, (1965) Prentice-Hall, Englewood Cliffs, N. J.

8) O. Kubachewski, E. L. Evans, and C. B. Alcock: Metallurgical Thermochemistry 4th Edition, (1968), Pergamon Press, London.

9) E. T. Turkdogan: Trans. TMS-AIME, 230 (1964), 740.

10) F. P. Calderon, N. Sano, and Y. Matsushita: to be published in Met. Trans.

11) E. T. Turkdogan, P. Grieveson, and L. S. Darken: J. Phys. Chem., 67 (1963), 1647.

12) J. Chipman and R. Baschwitz: Trans. TMS-AIME, 227 (1963), 473.

\section{Appendix}

In the foregoing paper, the boundary layer for heat transfer $\delta_{T}$ was assumed to be equal to that for mass transfer of $\mathrm{CO}_{2}, \delta_{\mathrm{CO}_{2}}$. However, $\delta_{T}$ is theoretically different from $\delta_{\mathrm{CO}_{2}}$, so that the values of $\delta_{T}$ are estimated in Appendix by using the following dimensionless equation analogous to Eq. (8), and then the influence of the correction of $\delta_{T}$ on the numerical values in Table 1 was inspected.

$$
\begin{gathered}
\mathcal{N} u=2+0.5\left(G r^{\prime \prime} \cdot \operatorname{Pr}\right)^{0.25}+n\left(\operatorname{Re} \cdot \operatorname{Pr} r^{0.5}\right)^{0.62} \\
\text { where } \quad G r^{\prime \prime}=G r_{H}+\left(\frac{P r}{S c}\right)^{0.5} \cdot G r_{M}
\end{gathered}
$$

At the same time, the activity of silicon in liquid iron recently measured by R. J. Fruehen (Met. Trans., 
Table A. Summary of recalculations for the condensation of $\mathrm{SiO}\left(P_{\mathrm{CO}_{2}}=0.0264,500 \mathrm{ml} / \mathrm{min}, 1700^{\circ} \mathrm{C}\right)$

\begin{tabular}{|c|c|c|c|c|c|c|c|c|c|c|c|c|}
\hline \multirow{2}{*}{$\begin{array}{l}\text { Weight } \\
\text { (g) }\end{array}$} & \multirow{2}{*}{$\frac{\mathrm{Si}}{(\%)}$} & \multicolumn{2}{|c|}{$\begin{array}{c}k\left(\mathrm{moles} / \mathrm{cm}^{2} \mathrm{sec}\right) \\
\times 10^{4}\end{array}$} & \multirow{2}{*}{$\begin{array}{c}T_{c} \\
\left({ }^{\circ} \mathrm{K}\right)\end{array}$} & \multicolumn{2}{|c|}{$\delta(\mathrm{cm}) \times 10^{2}$} & \multirow{2}{*}{$\begin{array}{l}\chi_{c}(\mathrm{~cm}) \\
\times 10^{2}\end{array}$} & \multirow{2}{*}{$\begin{array}{c}P o(\mathrm{~atm}) \\
\times 10^{3}\end{array}$} & \multirow{2}{*}{$\begin{array}{l}P e(\mathrm{~atm}) \\
\quad \times 10^{5}\end{array}$} & \multirow{2}{*}{$\begin{array}{l}P n(\mathrm{~atm}) \\
\times 10^{4}\end{array}$} & \multirow{2}{*}{$s$} & \multirow{2}{*}{$\delta_{T} / \delta_{\mathrm{CO}}$} \\
\hline & & $\mathrm{CO}_{2}$ & $\mathrm{SiO}$ & & $\mathrm{CO}_{2}$ & $\mathrm{SiO}$ & & & & & & \\
\hline 0.7 & 5.85 & 3.71 & 10.5 & 1361 & 16.0 & 6.39 & 5.85 & 4.62 & 1.12 & 3.94 & 25.34 & 1.003 \\
\hline 1.4 & 1.32 & 3.49 & 9.61 & 1253 & 17.0 & 7.89 & 7.41 & 2.57 & 0.105 & 1.60 & 151.6 & 1.017 \\
\hline
\end{tabular}

1, (1970), 865) was used for the recalculation instead of reference (12). The activity coefficient of silicon at $1700^{\circ} \mathrm{C}$ was estimated from his data at $1600^{\circ} \mathrm{C}$, assuming the regular solution. This gave the greater activities of silicon by a factor of 2.8 and 2.1 than the previous values at $1.32 \% \mathrm{Si}$ and $5.85 \%$, respectively.

The results of the recalculation are tabulated in Table A.
The values of $\delta_{T} / \delta_{\mathrm{CO}_{2}}$ are almost equal to unity for both cases, so that the significant change in the numerical values should be mainly due to the choice of the activity data. However, the fact that the estimated degrees of supersaturation greatly exceed or nearly equal unity should be a good evidence for the possibility that the formation of $\mathrm{SiO}$ may be enhanced by the condensation within the boundary layer. 